\title{
A HEAT PUMP SYSTEM WITH A LATENT HEAT STORAGE UTILIZING SEAWATER INSTALLED IN AN AQUARIUM
}

\author{
S.Okamoto*, K.Nada**, T.Kuriyama*** and M.Koyama*** \\ * Department of Mathematics and Computer Science, Shimane University, \\ 1060 Nishikawatsu, Matsue, Shimane 690-8504, Japan \\ ** The Chugoku Electric Power Co., Inc., 4-33 Komachi, Naka-ku, Hiroshima 730-8701, Japan \\ *** Nikken Sekkei Ltd., 4-6-2 Koraibashi, Chuo-ku, Osaka 541-8525, Japan
}

\begin{abstract}
This paper introduces a heat pump system with a latent heat storage utilization seawater installed in an aquarium. For heating purpose such as air conditioning in order to maintain the indoor conditions at constant temperature and constant relative humidity, and cooling water supply to the fish tank in the aquarium, heat from seawater is collected as the heat source for the heat pump system. With regard to the heat pump system using low-temperature unutilized heat source, development is introduced on a heat source load responsive heat pump system, with combines a load variation responsive heat pump utilizing seawater with a latent heat (ice plus water slurry) storage system using nighttime electric power serving for electric power load leveling. The objective of this study is to compare the actual operating characteristics and efficiency of a seawater-source heat pump with ice storage system to the predicted evaluation of the two assumed conventional system. The experimental COP (Coefficient of performance) of the proposed heat exchanger from seawater and latent heat storage cooling assisted heat pump system will be shown in detail.
\end{abstract}

Kevwords: Heat Pump, Latent Heat Storage. Unutilized Energy, Aquarium, COP

\section{INTRODUCTION}

In order to reduce the emission of carbon dioxide and thereby to protect against global warming, the effective use of energy such as the efficient use of various types of waste heat and renewable energy should be promoted. A heat pump system can produce more heat energy than the energy which is used to run the heat pump system. Thus, a heat pump system is considered to be one of the representative of the machine system which can use energies efficiently, and the load leveling air conditioning system utilizing unutilized energies at high levels [1-3].

This paper introduces a heat pump system with a latent heat storage utilizing seawater installed in an aquarium. For heating purpose such as air conditioning in order to maintain the indoor conditions at constant temperature and constant relative humidity, and cooling water supply to the fish tank in the aquarium, heat from seawater is collected as the heat source for the heat pump system. With regard to the heat pump system using low-temperature unutilized heat sources, development is introduced on a heat source load responsive heat pump system, which combines a load variation responsive heat pump utilizing seawater with a latent heat (ice plus water slurry) storage system using nighttime electric power serving for electric power load leveling. The experimental COP (Coefficient of performance) of the proposed heat pump with the latent heat storage cooling system will be shown in detail.

Tests were run in the aquarium for two years. Overall performance characteristics of particular interest were integrated $\mathrm{COP}$ along with other instantaneous comparison of power, refrigerant flow rate and temperature. This heat pump system has two operational modes: The first is the ice plus water slurry cooling mode that is a typical mode in summer. In this mode, the ice is produced using the heat pump connected with the latent heat storage system. The second is the winter mode. In this mode, the circulating water is heated by the heat pump connected with the heat exchanger system to collect heat from the seawater and the ambient air. Energy saving effects and carbon dioxide reducing effects of the heat pump system are estimated by tests.

The objective of this study is to compare the actual operating characteristics and efficiency of a seawater-source heat pump with ice storage system to the predicted evaluation of the two assumed conventional system, that is, an air-source heat pump without ice storage, and oil-fired absorption refrigerating system. The desired outcome would be to show that the seawater-source heat pump uses significantly less electricity than the air-source heat pump and the oil-fired system. Additionally, the $\mathrm{CO} 2$ emissions for the seawater-source heat pump compare favourably as they maybe less than those for the other conventional assumed system described.

\section{NOMENCLATURE}

AWSHP003: Seawater- and air-source heat pump 003 COP: Coefficient of performance

$\mathrm{CT}$ : Cooling tower

$\mathrm{HX}$ : Heat exchanger

IS: Ice storage tank

P: Pump 


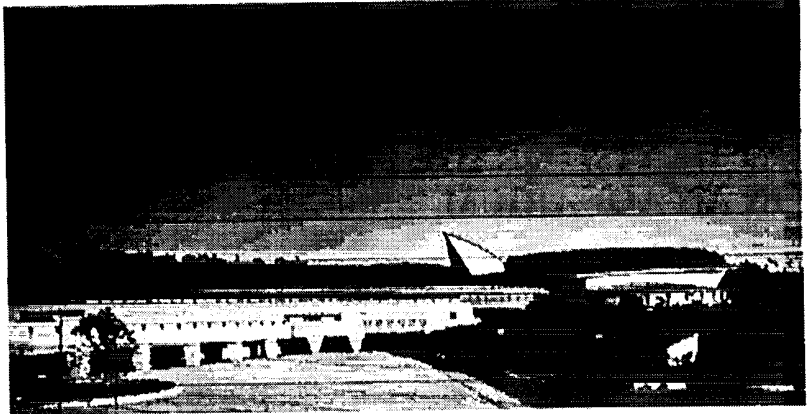

Fig.1 A view of Shimane Aquarium (AQUAS)

PU: Power unit

WSHP001: Seawater-source heat pump 001

WSHP002: Seawater-source heat pump 002

Subscript

ac: Air conditioning

b: Brine

cf: Cooling for fish tank

$\mathrm{cw}$ : Cooling water

hf: Heating for fish tank

hw: Heating water

sw: Seawater

ts: Thermal energy storage

w: Cooling and heating water

\section{SYSTEM DESCRIPTION}

Shimane Aquarium (AQUAS) locates an area facing Japanese Sea (Shimane Prefecture in Japan). Figure 1 is a view of the Aquarium. The total floor area in the building is $10,293 \mathrm{~m}^{2}$, the numbers of storeys are 2 (+ cellar), and the bulk of the fish tank is $3,000 \mathrm{~m}^{3}$.

The primary cooling loads at the aquarium are building air conditioning, cooling of ventilation air for the fish tank, and cooling and heating of the water in the fish tank. The system selected is one that combines two seawater-source heat pumps, WSHP001 and WSHP002 (cw: $650 \mathrm{~kW}$, hw: $732 \mathrm{~kW}$ ) and a heat recovery type air-source heat pump, AWSHP003 (cw: $510 \mathrm{~kW}$, hw: 697 $\mathrm{kW}$ ). Seawater-source heat pumps transfer heat to and from the seawater by means of circulated water and heat exchanger. Air-source heat pump uses the outdoor air for heat absorption and rejection. Air-source heat pump is more common because of its lower initial cost and ease of installation, but seawater-source heat pump is more energy efficient. The heat pump tested in this work transfers heat to the outdoor air and to the sea. It maintains some of the initial cost advantages of the air-source heat pump and some of the performance advantages of the seawater-source heat pump.

These provide cooling of water using off-peak power. The primary heat source is the heat collected from the seawater and stored in the ice storage tank, IS (ts: 4,500 $\mathrm{kWh} \times 2$ ). The heat produced by the heat pump at night is stored in the ice storage tank. Figure 2 is a diagram of the system. In general, the increased efficiency of the seawater-source heat pump is gained by two mechanisms. First, water is a much better heat transfer fluid than air, so heat is moved much more efficiently. Second, the seawater allows the heat pump to extract heat from water that is usually warmer than the outside air during the winter and cooler than the outside air during the summer. This allows more efficient heat pump operation. The seawater-source heat pump usually provides warmer supply air temperature during the winter and cooler supply air temperature during the summer, which increases comfort levels.

Ice storage technology has been shown to be effective in reducing operating cost of cooling equipment during the summer time. By operating the refrigeration equipment during off-peak hours to recharge the ice storage, and discharge the storage during on-peak hours, a significant fraction of the on-peak electrical demand and energy consumption is shifted to off-peak periods. Cost saving is realized because utility rates favor leveled energy consumption patterns. The variable rates reflect the high cost of providing energy during relatively short on-peak periods. Hence, they constitute an incentive to reduce or

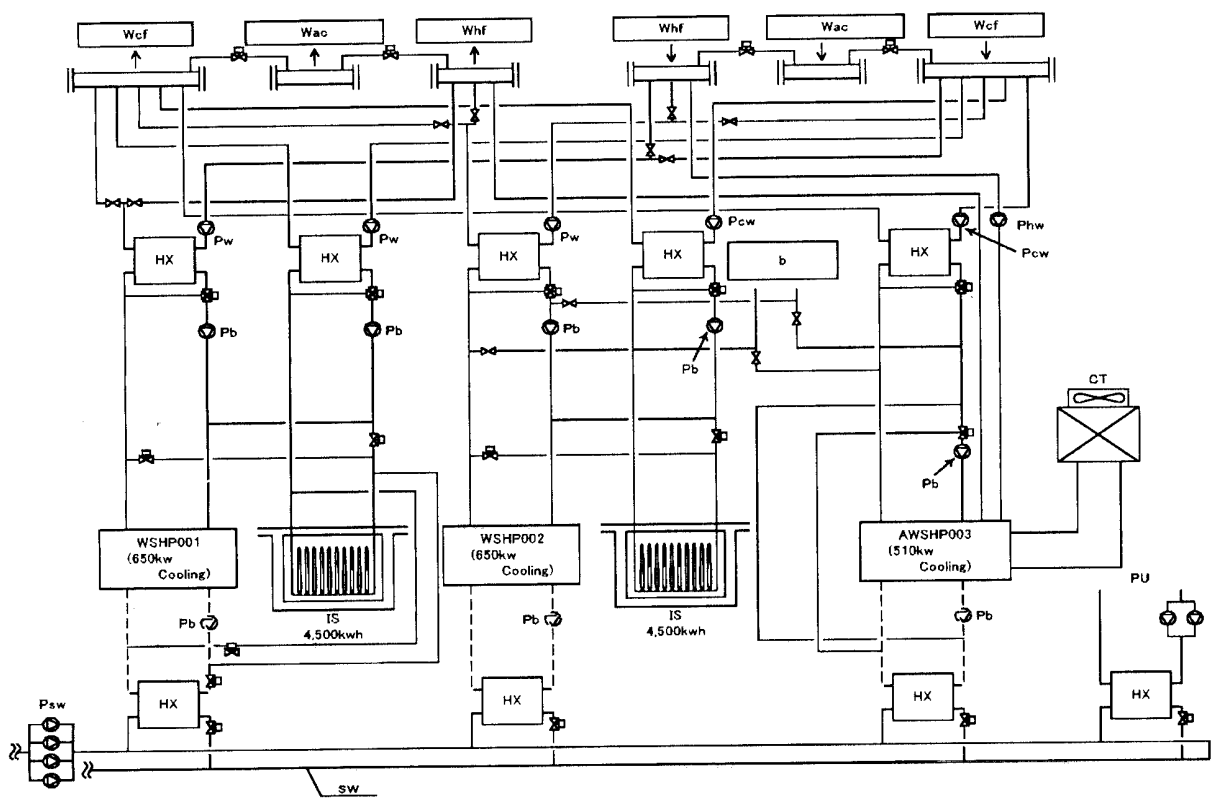

Fig.2 Diagram of heat pump system in aquarium 


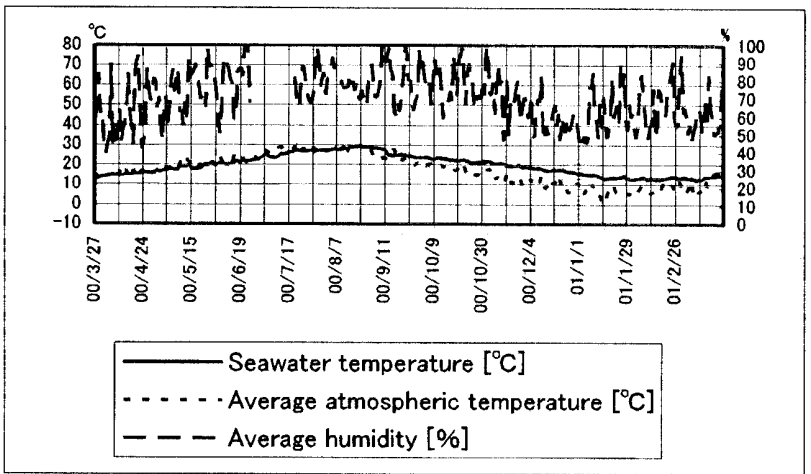

Fig.3 Seawater temperature, air temperature and humidity

avoid operation of the cooling plant on-peak periods by cool storage. The large differential between on- and off-peak energy and peak consumption rates should make cold storage system economically feasible.

\section{RESULTS AND DISCUSSION}

\section{Loads of Building throughout the Year}

Figure 3 shows the ambient air temperature, the ambient air humidity, and the seawater temperature throughout the year. The maximum temperature on August was $35.9{ }^{\circ} \mathrm{C}$, and the averaged temperature was $28.3{ }^{\circ} \mathrm{C}$. Relative humidity ranged from about $70 \%$ at night to $95 \%$ during the day on August.

Figure 4 shows the daily loads of the cooling air-conditioning for the space above the fish tank, cooling water and heating water for the fish tank, and air-conditioning for the building during the period from March 27, 2000 to March 10,2001. The loads of the air-conditioning for the building in the period of summer time exceeded the predicted loads, but loads in the winter were about $70 \%$ of the predicted loads. The loads of the cooling water and cooling air-conditioning for the fish tank have been stable and constant since May. The loads of cooling water for the fish tank could be generated during only the summer time, but the loads of heating water for the fish tank could be produced during only the winter.

The primary cooling loads at the aquarium are cooling of cold water in the fish tank, and cooling of ventilation air in the building. Figure 5 shows the typical building cooling use on a typical summer day from August 14 to August 20, 2000. The loads of the cooling air-conditioning have been about constant every day. The loads of the cooling of ventilation air in the building and the cooling of water in the fish tank were greatest in the afternoon because of hotter outside air. The outside air temperature increase and, combined with solar gains, lighting, and a large audience energy gains, the cooling loads increased during the day. The relationship of cooling air-conditioning and cooling water loads is an important consideration with the type of heat pump system installed in the aquarium. This is because the heat pump produces aquarium cooling water from seawater-source heat and air-source heat.

Winter days tend to be warm in Shimane Prefecture. As an example, Figure 6 shows typical aquarium heating and air-conditioning use on a typical winter day from January 15 to January 21, 2001. These data are operator records during these periods. On these days, the plant has been running to maximize heating, using air to warm each individual building's system. By reducing the amount of outside air used in the building, the heat needed is also reduced while the amount of heating (heat recovery) is increased. When using minimum outside air, the major heat use (after initial building warm-up) is for air-conditioning. On an average winter days, large heating (heat recovery) loads could be generated from heating water for the fish tank.

\subsection{Energy Usage}

Figure 7 compares the daily electrical consumption of the three heat pumps from March 27, 2000, until February 26, 2001. During the first two months after the kilowatt-hour meters were installed, the AWSHP003 used about $22 \%$ of the electricity that the building used. Averaged energy usage for those months was $3900 \mathrm{kWh}$ per day for the AWSHP003. This included both heating and cooling modes of operation, with the transition from heating to cooling occurring in April. The electrical requirements of the AWSHP003 remained relatively constant throughout the year. AWSHP003 was running through all day long. The load factor of this heat pump was $50 \%$ during the period of the cooling and air-conditioning in the summer time, and the load factor was about $60 \%$ during the period of the heating in the winter.

The WSHP001 and 002 used relatively more energy during the summer than during the winter. Overall, for the period from April 15 to November 21, 2000, the WSHP001 and 002 have used about $80 \%$ of the energy that the AWSHP003 has used. The electrical energy use of both WSHP001 and 002 has peaked during this period from August 14 to August 20 because of the heavy air-conditioning load of the building. Both WSHP001 and 002 supply only the cooling energy for the air-conditioning of the building and the cooling water for the fish tank during the summer time. With more data from the winter months, it was expected that the energy use of the WSHP001 and 002 would approach about zero. WSHP001 and 002 have been stopping expect the period of the maintenance of the AWSHP003 during the period of the heating in the winter.

Figure 8 shows the typical energy consumption of the WSHP001 and 002 for the period after the kilowatt-hour meters were installed in March, 2000. Periodic readings began after August 14, and weekly readings have been conducted until August 20, 2000. Both of the WSHP001 and 002 have been fully running after initial building opening in the morning, and have been stopping during the period from 1:00 p.m. to 4:00 p.m. in the afternoon, and have been running with the ice storage tanks according to the loads from 4:00 p.m. again. Summer days tended to produce more energy from cooling than was needed, and the ice storage tanks run at night to produce ice and water slurry to charge the ice storage tank. Cooling heat was picked up by the ice storage system, resulting in warmer chilled water return. This warmer chilled water return was stored in the ice storage tank. Viewed as a heat source for the building, this increase in ice and slurry water temperature was (potential) heat storage.

The heat pump operating at night removed energy 


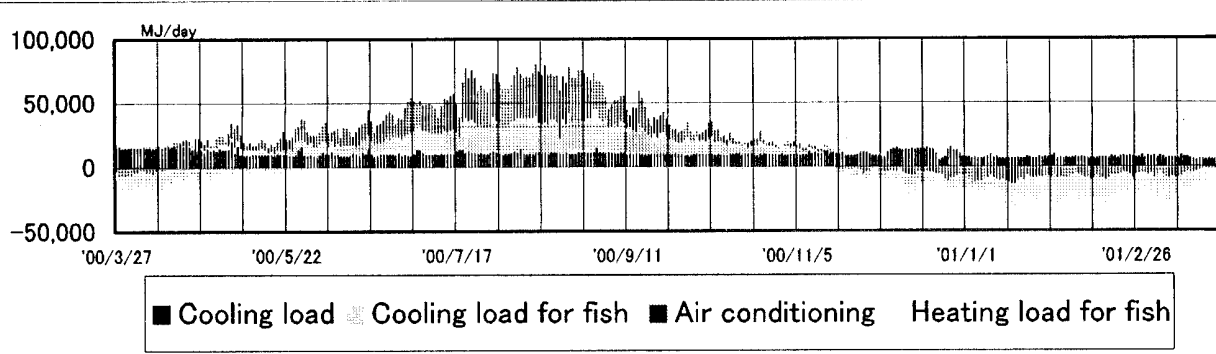

Fig.4 Daily loads of building in the year

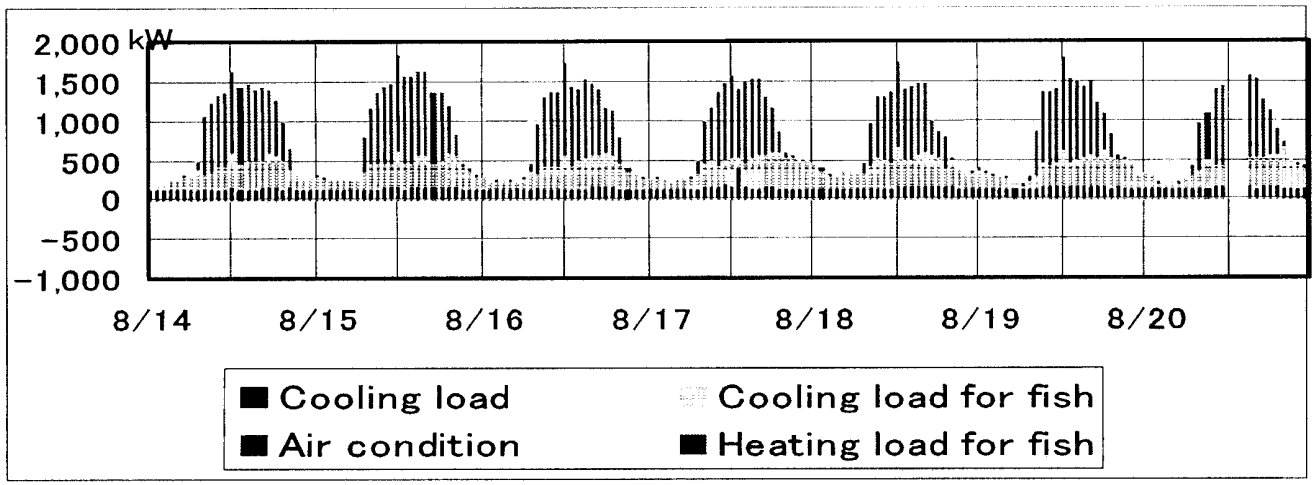

Fig.5 Hourly loads of building in summer

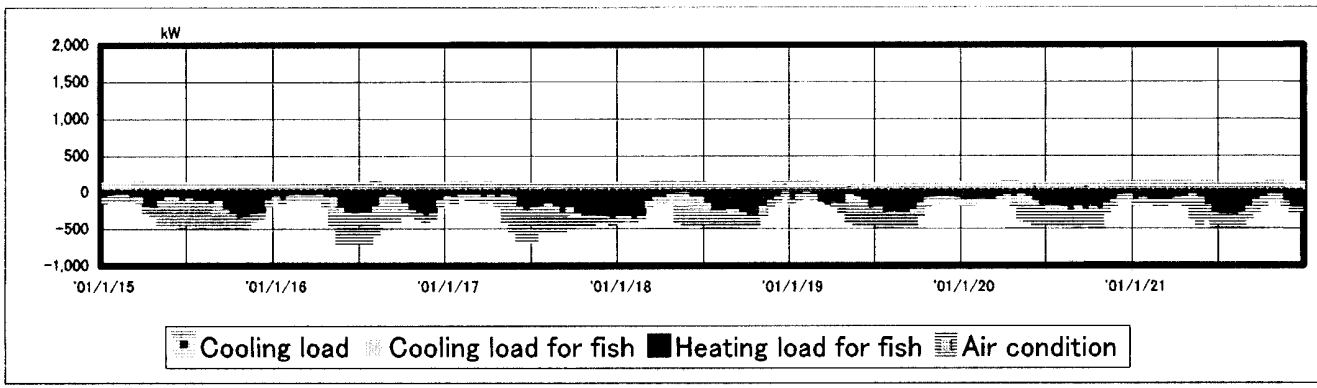

Fig.6 Hourly loads of building in winter

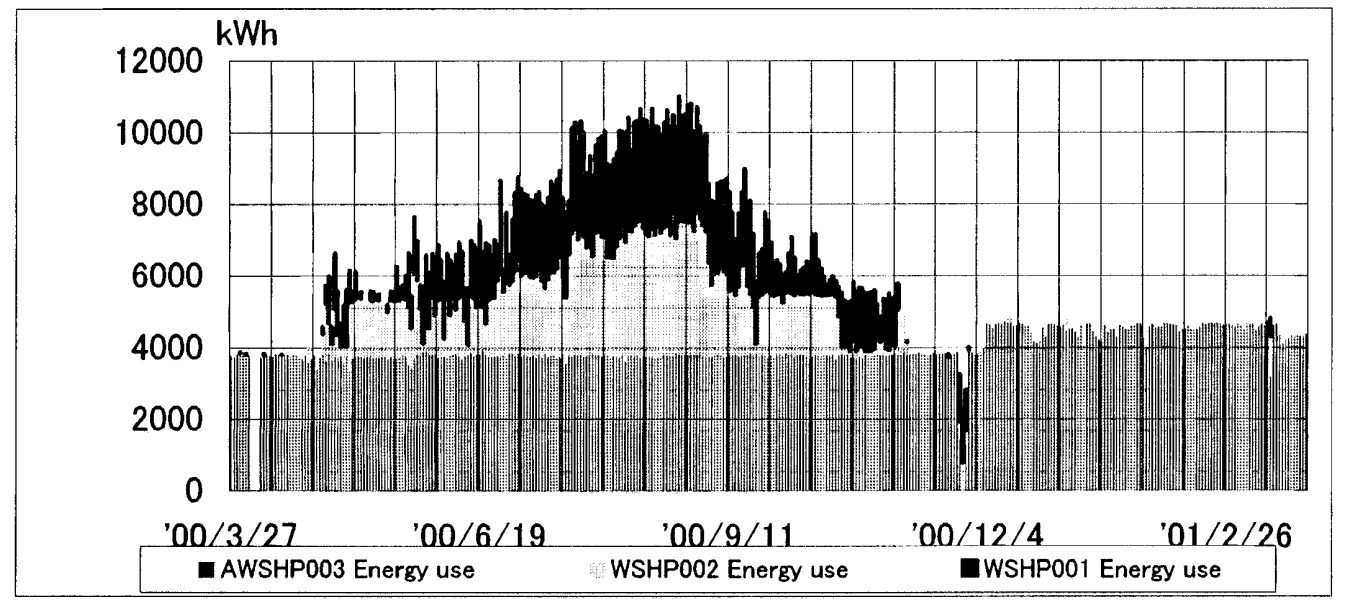

Fig.7 Daily electrical consumption of three heat pumps 


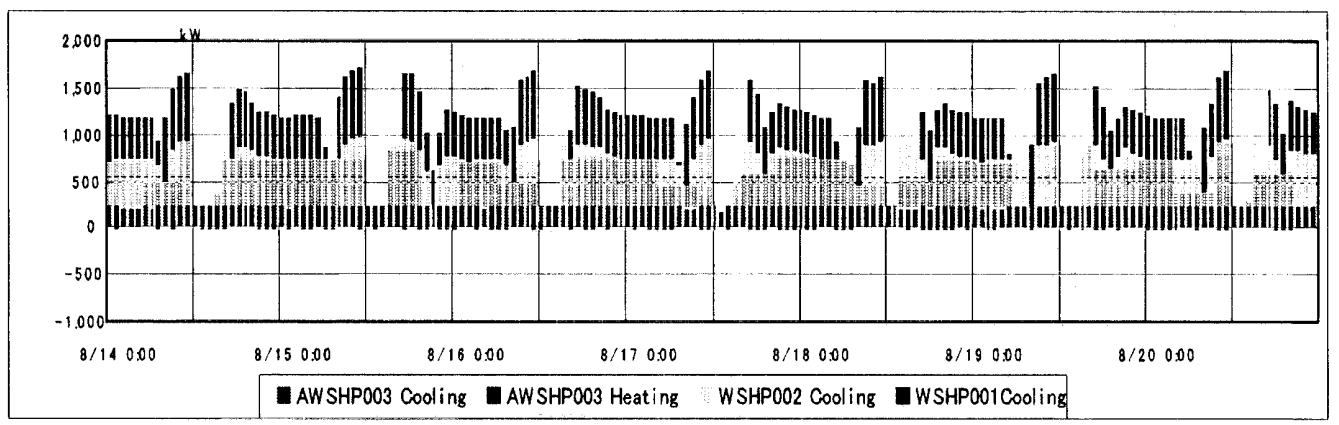

Fig.8 Hourly energy consumption of building in summer

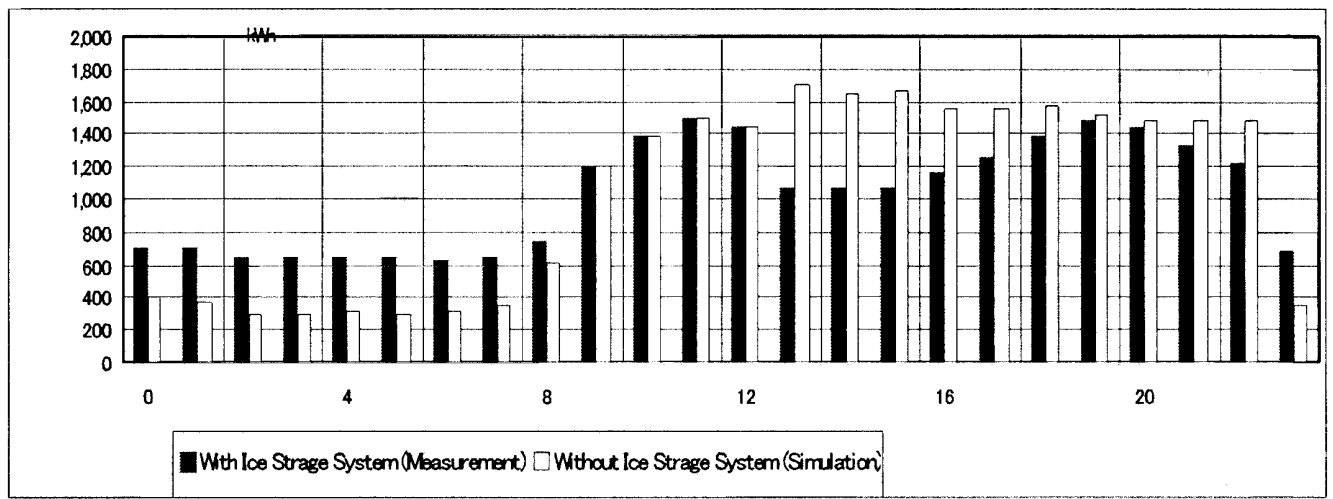

Fig.9 Shift of peak loads

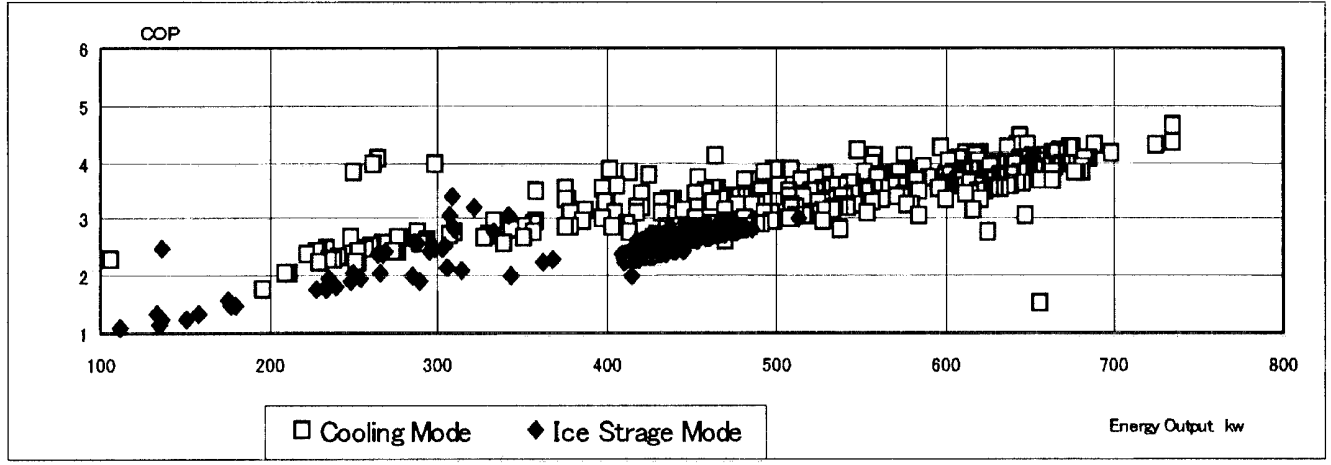

Fig.10 COP of WSHP001

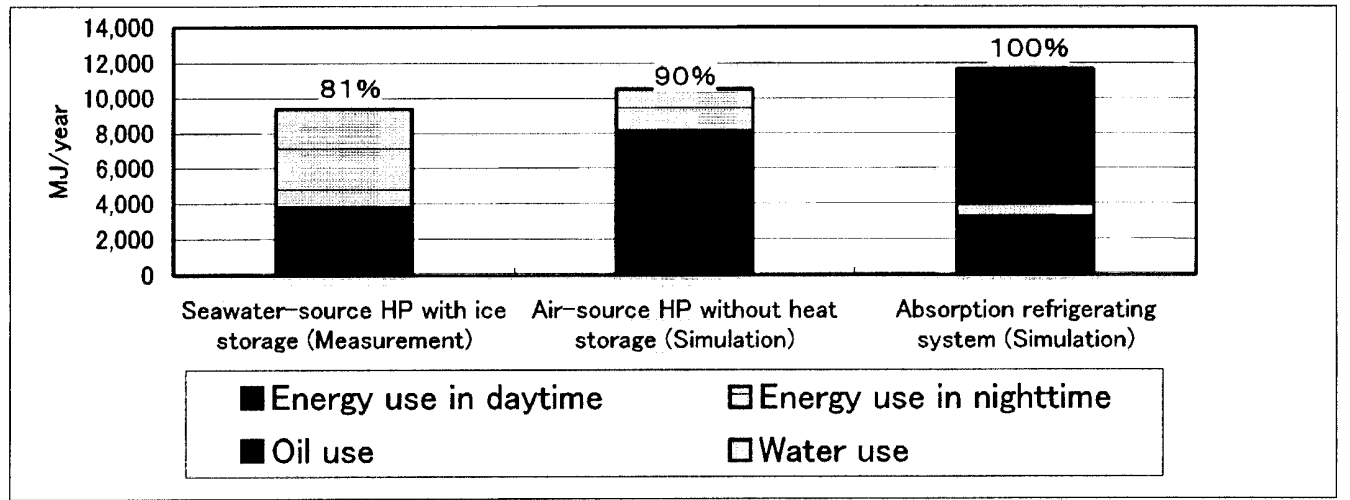

Fig.11 Reduction of energy consumption of WSHP001 and 002 
from the seawater and produced cooling water, which was stored in the ice storage tank. The ice and water slurry were used during the next day, with the largest loads early in the afternoon. The ice storage system provided a match in time between cooling availability and the time of the heat need. By operating the refrigeration equipment during off-peak hours to recharge the ice storage, and discharge the storage during on-peak hours, a significant fraction of the on-peak electrical demand and energy consumption was shifted to off-peak periods (Fig.9). It also provided the means to recover and produce cooling at the lowest possible cost by using off-peak electrical energy.

\subsection{Energy Efficiency}

Summer mode was most efficient for two reasons. The owner received full benefit from air conditioning for the building and water cooling for the fish tank at the same time. Also, the cold water from the ice storage tanks kept the condensing temperature, which in turn reduced the work done by the heat pumps. When operating in winter mode the AWSHP003 obtained its heat from outdoor air and accrued air-conditioning benefit. However, the cold water benefit was still taking place. We found from monitoring that the Coefficient of performance (COP) was relatively high, averaging 3.4 for the summer time. When operating in summer mode with ice storage, COP of WSHP001 was 2.6, and COP of WSHP002 was 3.0 for output for each unit of energy (electricity) used (Fig.10). This was the best use of resources and was quite remarkable when considering that it operated in this mode for $60 \%$ of the time on a year-round basis.

In winter, when the unit was operating mainly in winter mode the COP was quite low. The COP was even lower for AWSHP003 than WSHP001 and 002, even though it was working throughout the year. By checking the daily results it was found that the partial load running was often done for the most part of running time to allow a very low COP. Another reason for decreased COP of AWSHP003 was due to the heat-recovery running mode, even though the heating loads were almost zero.

The performance of the heat pumps with the ice storage system have been compared to two other systems (assumed systems), which have been installed in the aquarium where heating and cooling are supplied with combinations of the air-source heat pump system without ice storage, and oil-fired absorption refrigerating system. The COP of the absorption refrigerating system was assumed to be 1.0 in cooling time, and to be 0.9 in warming time. Energy consumptions of the other two alternative systems were calculated by means of the assumed values of these systems. Energy consumption of the WSHP001 and 002 was $19 \%$ less than in the oil-fired absorption refrigerating system (Fig.11).

The emissions of this system were 86 tons of $\mathrm{CO} 2$ in a year. This compared favourably to the emissions of the other alternatives for heating and cooling in the two other systems (assumed results): the emissions of the air-source heat pump system without ice storage were 102 tons of $\mathrm{CO} 2$, and the emissions of the oil-fired absorption refrigerating system were 176 tons of $\mathrm{CO} 2$. The emissions of $\mathrm{CO} 2$ were estimated at $84 \mathrm{~g}-\mathrm{C} / \mathrm{Mcal}$ in the oil, at 103 $\mathrm{g}-\mathrm{C} / \mathrm{kWh}$ in the electricity for day time, and at $83 \mathrm{~g}-\mathrm{C} / \mathrm{kWh}$ in the electricity for night time. The $\mathrm{CO} 2$ emissions of the electric heat pump with ice storage were two times less than those of the oil-fired system for heating and cooling (Fig.12).

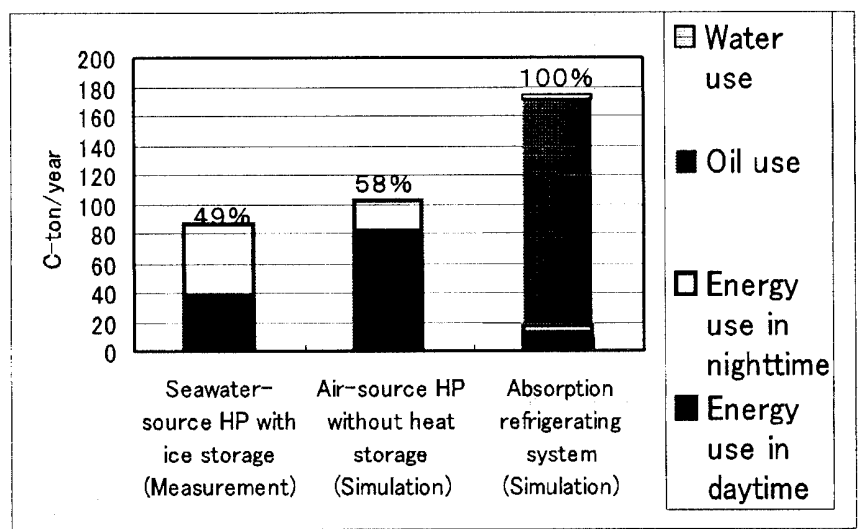

Fig.12 Reduction of CO2 emissions of WSHP001 and 002

\section{CONCLUSIONS}

A seawater-source heat pump system installed in a new-built aquarium in Shimane Prefecture in Japan provided simultaneous heating and cooling. A COP of WSHP001 at running conditions was 3.4 for cooling and 2.8 for ice storage. By operating the refrigeration equipment during off-peak hours to recharge the ice storage, and discharge the storage during on-peak hours, a significant fraction of the on-peak electrical demand and energy consumption was shifted to off-peak periods. In the following this case study was compared to two other assumed systems in which heating and cooling was supplied by the conventional air-source heat pump and the conventional oil-fired refrigerant. The energy consumption of the seawater-source heat pump for heating and cooling was $19 \%$ lower than in the oil-fired absorption refriger ating system. Also, the $\mathrm{CO} 2$ emissions for heating and cooling compared favourably as they were two times less than those for the oil-fired system described.

\section{ACKNOWLEDGIMENTS}

We wish to thank the staff of The Aquarium (AQUAS) in Shimane Prefecture for assisting with the project.

\section{REFERENCES}

1. Brodrick, J.R., and Westphalen, D., Uncovering Auxiliary Energy Use, ASHRAE Journal, Vol.43, No.2, (2001), pp.58-61.

2. Kavanaugh, S.P., and Lan Xie, Energy Use of Ventilation Air Conditioning Options for Ground-Source Heat Pump System, ASHRAE Transactions: Symposia, MN-00-5-2, (2000), pp.543-550.

3. Phetteplace, P.E., and Sullivan, W., Performance of a Hybrid Ground-Coupled Heat Pump System, ASHRAE Transactions: Symposia, Vol.104, Part 1, (1998), pp.763-770. 